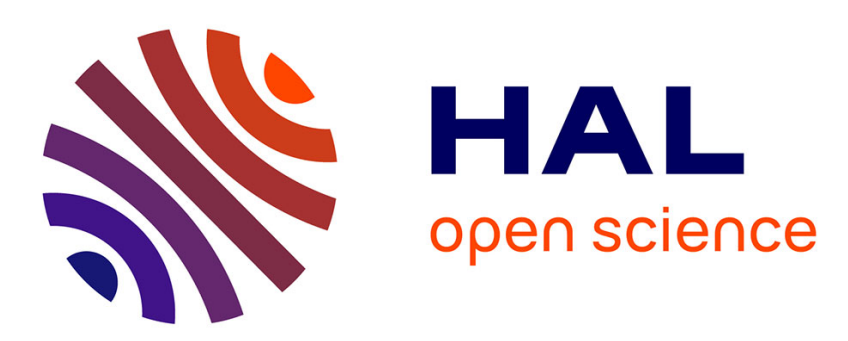

\title{
Direct visualization of carbon nanotube degradation in primary cells by photothermal imaging
}

Julie Russier, Laura Oudjedi, Martin Piponnier, Cyrill Bussy, Maurizio Prato, Kostas Kostarelos, Brahim Lounis, Alberto Bianco, Laurent Cognet

\section{- To cite this version:}

Julie Russier, Laura Oudjedi, Martin Piponnier, Cyrill Bussy, Maurizio Prato, et al.. Direct visualization of carbon nanotube degradation in primary cells by photothermal imaging. Nanoscale, 2017, 9 (14), pp.4642-4645. 10.1039/c6nr09795b . hal-01630832

\section{HAL Id: hal-01630832 https://hal.science/hal-01630832}

Submitted on 8 Nov 2017

HAL is a multi-disciplinary open access archive for the deposit and dissemination of scientific research documents, whether they are published or not. The documents may come from teaching and research institutions in France or abroad, or from public or private research centers.
L'archive ouverte pluridisciplinaire HAL, est destinée au dépôt et à la diffusion de documents scientifiques de niveau recherche, publiés ou non, émanant des établissements d'enseignement et de recherche français ou étrangers, des laboratoires publics ou privés. 


\title{
Direct visualization of carbon nanotube degradation in
}

\section{primary cells by photothermal imaging}

\author{
Julie Russier, ${ }^{1}$ Laura Oudjedi, ${ }^{2,3}$ Martin Piponnier, ${ }^{2,3}$ \\ Cyrill Bussy, ${ }^{4}$ Maurizio Prato, ${ }^{5,6,7}$ Kostas Kostarelos, ${ }^{4}$ Brahim Lounis, ${ }^{2,3}$ Alberto Bianco, ${ }^{1 *}$ \\ Laurent Cognet ${ }^{2,3 *}$ \\ ${ }^{1}$ University of Strasbourg, CNRS, Immunopathology and therapeutic chemistry, UPR 3572, \\ 67000 Strasbourg, France \\ ${ }^{2}$ University of Bordeaux, LP2N, F-33405 Talence, France \\ ${ }^{3}$ Institut d'Optique \& CNRS, LP2N, F-33405 Talence, France \\ ${ }^{4}$ Nanomedicine Laboratory, Faculty of Biology, Medicine and Health and National Graphene \\ Institute, University of Manchester, AV Hill Building, Manchester M13 9PT, United

\section{Kingdom} \\ ${ }^{5}$ Dipartimento di Scienze Chimiche e Farmaceutiche, Università di Trieste, Trieste 34127, \\ Italy \\ ${ }^{6}$ Carbon Nanobiotechnology Laboratory, CIC biomaGUNE, Paseo de Miramón 182, 20009 \\ Donostia-San Sebastian (Spain) \\ ${ }^{7}$ Basque Fdn Sci, Ikerbasque, Bilbao 48013, Spain
}

Corresponding authors: 1aurent.cognet@u-bordeaux.fr; $\underline{\text { a.bianco@,ibmc-cnrs.unsitra.fr }}$ 
Keywords: Carbon nanotubes, functionalization, biodegradation, microglia, photothermal imaging

Assessment of biodegradability of carbon nanotubes (CNTs) is a critically important aspect that needs to be solved before their translation into new biomedical tools. CNT biodegradation has been shown both in vitro and in vivo, but we are limited by the number of analytical techniques that can be used to follow the entire process. Photothermal imaging $(\mathrm{PhI})$ is an innovative technique that enables the quantitative detection of nanometer-sized absorptive objects. In this study, we demonstrate that $\mathrm{PhI}$ allows observation of the degradation process of functionalized multi-walled carbon nanotubes (MWCNTs) following their internalization by primary glial cells. The absence of interference from the biological matrix components, together with the possibility to combine $\mathrm{PhI}$ with other detection techniques (e.g. fluorescence, light or electron microscopy) validate the potential of this method to follow the fate and behavior of carbon nanostructures in a biological environment.

The demonstration of the degree of carbon nanotube (CNT) biodegradation is still a challenge in their development for biomedical applications. ${ }^{1}$ Although it has been reported that different types of CNTs displayed diverse outcomes when placed in an oxidative environment, there is still a limited number of studies proving their biodegradability in living systems. ${ }^{2-4}$ This might be related in part to the very short list of versatile analytical techniques applicable to detect the nanotubes and their fate in cells and organs. Two techniques are commonly employed to follow the progress of CNT degradation: i) transmission electron microscopy (TEM), and ii) Raman spectroscopy or imaging.,

TEM enables visualization of the CNT physical structure evolution and measurement of the changes in CNT length and diameter during the incubation with oxidative enzymes. ${ }^{2,3,6}$ 
However, TEM has certain limitations particularly when performed directly in biological matrices such as cells and tissues, where the contrast of organic components (i.e. carbon based) might hamper a clear identification of degrading carbon nanotubes.

Raman spectroscopy is also a powerful tool to evaluate the integrity of CNT crystalline structures that can then be extrapolated to their physical structures. ${ }^{7}$ In fact, CNTs have two main characteristic bands in the Raman spectrum, corresponding to $G\left(\sim 1590 \mathrm{~cm}^{-1}\right)$ and $D$ $\left(\sim 1350 \mathrm{~cm}^{-1}\right)$ bands, describing the graphitic structure of CNT sidewalls and the defect sites, respectively. ${ }^{8}$ It is easy to recognize and follow the evolution of these two signals along the degradation process. Nevertheless, Raman also presents some limitations. Even in absence of degradation, it is difficult to analyze some MWCNTs that have a strong D band due to the presence of high amount of defects on their sidewalls. Secondly, Raman gives information only about the sidewall structure of CNTs but provides no data about their length, which has been proven to be shortened by oxidative enzymes during their biodegradation. ${ }^{2,3,6}$ Finally, the definition of the Raman signal and therefore the analysis of Raman spectra are highly affected by the auto-fluorescence of biological specimen and the selection of substrate used to collect the Raman signal. Although the combination of TEM and Raman helps in an overall analysis of the biodegradation process, ${ }^{5,6,9,10}$ the use of alternative techniques with lower interference from the biological matrix components could be highly advantageous to study in situ the CNT degradation in complex biological systems.

In this context, photothermal imaging (PhI) could be a good candidate, as it enables the efficient detection of nanometer-size objects solely based on their absorption, and does not share the burden of biological matrix component interference, observed with TEM or Raman based in situ degradation evaluations. The extreme sensitivity of $\mathrm{PhI}$ method and the stability of the signals have already opened the way to numerous applications in spectroscopy, analytical chemistry and bioimaging. ${ }^{11,12}$ Like Raman spectroscopy, $\mathrm{PhI}$ is an all optical method, and it is 
based on the detection of refractive index variations that are induced by photothermal effect in the local environment of an absorbing nanoparticle. ${ }^{13,14}$ A few variants of PhI exist, ${ }^{13,15,16}$ and photothermal heterodyne imaging, which is the most sensitive scheme, ${ }^{13,17}$ allows detecting several types of nano-objects at a single particle level. These include gold nanoparticles, even within a cell matrix and for membrane receptor dynamics studies in live cells, ${ }^{18,19}$ molecules, quantum dots or single walled carbon nanotubes. ${ }^{19-25}$ Interestingly, PhI signal intensities can be correlated to the dimension ${ }^{26}$ and concentration ${ }^{27}$ of the nanoparticles under investigation, while quantitative optical imaging of individual nanotubes down to $\sim 10 \mathrm{~nm}$ in length was possible. ${ }^{28}$ In addition, $\mathrm{PhI}$ is totally unaffected by non-absorbing scatterers, even when large objects with strong refractive index contrast are present within the surroundings of the imaged nanoparticles, as it is often the case in biological samples. In view of these advantageous characteristics we decided to explore the potential of this technique for the direct visualization of functionalized carbon nanotube degradation inside microglia, the resident macrophages of the central nervous system, and its evolution overtime. Here we based our demonstration on these primary microglial cells owing to previous experience with this model (same primary cells and same functionalized CNTs, see below) using TEM or Raman to assess degradation, hence providing a direct comparison with previously reported data. ${ }^{29}$

We thus used MWCNTs functionalized by 1,3-dipolar cycloaddition reaction, leading to cationic nanotubes $\left(\mathrm{MWCNT}-\mathrm{NH}_{3}{ }^{+}\right)\left(\right.$Figure 1) ${ }^{30,31}$

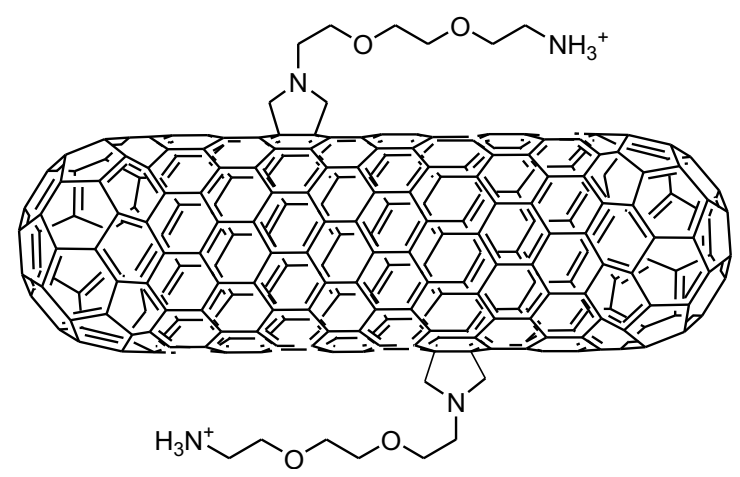

Figure 1. Molecular structure of functionalized multi-walled carbon nanotubes (MWCNT-NH ${ }_{3}{ }^{+}$). 
This type of nanotubes has been extensively used for different applications including therapy and imaging. ${ }^{32-34}$ In particular, they have been explored as carriers of small interference RNA for gene silencing. ${ }^{32,33} 1$ Their biodistribution and biodegradation have been also thoroughly assessed. ${ }^{5,35}$ In this context, we recently studied the kinetics of degradation of MWCNTs with different types of functionalization into long-term cultures of microglia using Raman spectroscopy. ${ }^{29}$ Functionalization including the 1,3-dipolar cycloaddition reaction was able to promote a continuous and progressive intracellular degradation of these different nanotubes over three months. ${ }^{29}$

Semi-thin or ultra-thin sections of about $500 \mathrm{~nm}$ and $70 \mathrm{~nm}$, respectively, are often used for TEM analysis of biological specimen embedded in resin. We thus decided to determine whether we could observe nanotubes and evaluate the progression of their degradation in microglial cells by $\mathrm{PhI}$ using semi-thin sections. $\mathrm{MWCNT}-\mathrm{NH}_{3}{ }^{+}$were first incubated with primary microglial cells for $24 \mathrm{~h}$. Cells were subsequently maintained in culture for different periods of times (1, 7 and 14 days) at the end of which the CNT loaded cells were fixed, embedded in resin and sectioned, before imaging by $\mathrm{PhI}$ (experimental setup in Figure S1). Figure 2 shows photoluminescence (GFP channel) and $\mathrm{PhI}$ images of representative regions of microglial cells that were incubated with $\mathrm{MWCNT}-\mathrm{NH}_{3}{ }^{+}$and then fixed after 1, 7 or 14 days of culture. For each of the three time points, $\mathrm{PhI}$ signal reveal the unambiguous presence of intracellular MWCNTs in comparison to cells that were not exposed to MWCNTs (Figure S2). Moreover, while MWCNT- $\mathrm{NH}_{3}{ }^{+}$were present in large aggregates inside cells at day 1 (Figure 2), they appeared more dispersed and more individualized after 14 days, suggesting their partial intracellular degradation or clearance (Figure 2). 


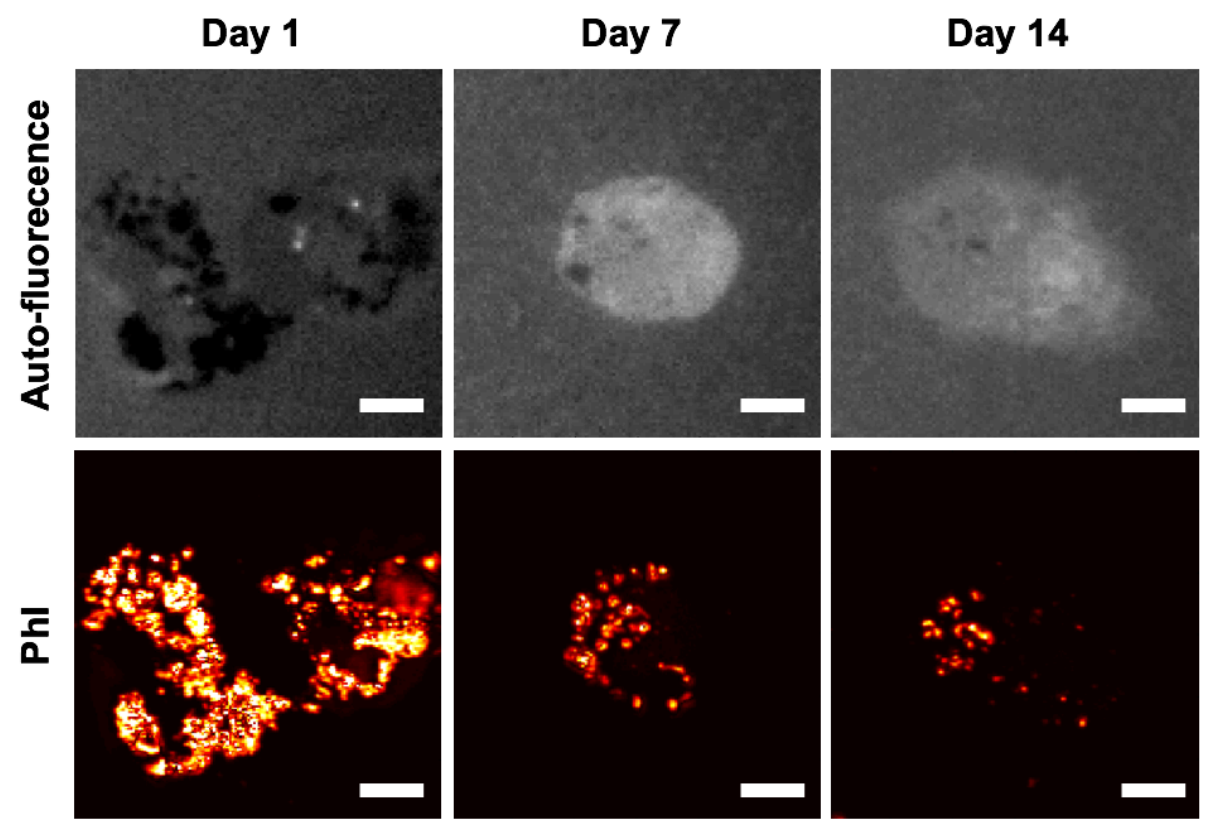

Figure 2. Photoluminescence (top row) and $\mathrm{PhI}$ images (bottom row) of $500 \mathrm{~nm}$ semi-thin sections of resin embedded microglial cells incubated with $\mathrm{MWCNT}-\mathrm{NH}_{3}{ }^{+}$at $10 \mu \mathrm{g} / \mathrm{ml}$ and then cultured for 1,7 and 14 days. Scale bar: $5 \mu \mathrm{m}$.

To further quantify these observations, we performed a systematic analysis of $\mathrm{PhI}$ signals by measuring the signal surface areas and the intensities detected in the cells at the different time points (Figure 3). After image segmentation, the cumulative histograms of the signal areas were plotted in Figure 3A, normalized to the point-spread function of the microscope $(\sim 290$ $\mathrm{nm}$, see Methods). In each segmented area, signal intensities defined as integrated signals normalized by the surface areas were also measured and displayed in Figure 3B. 

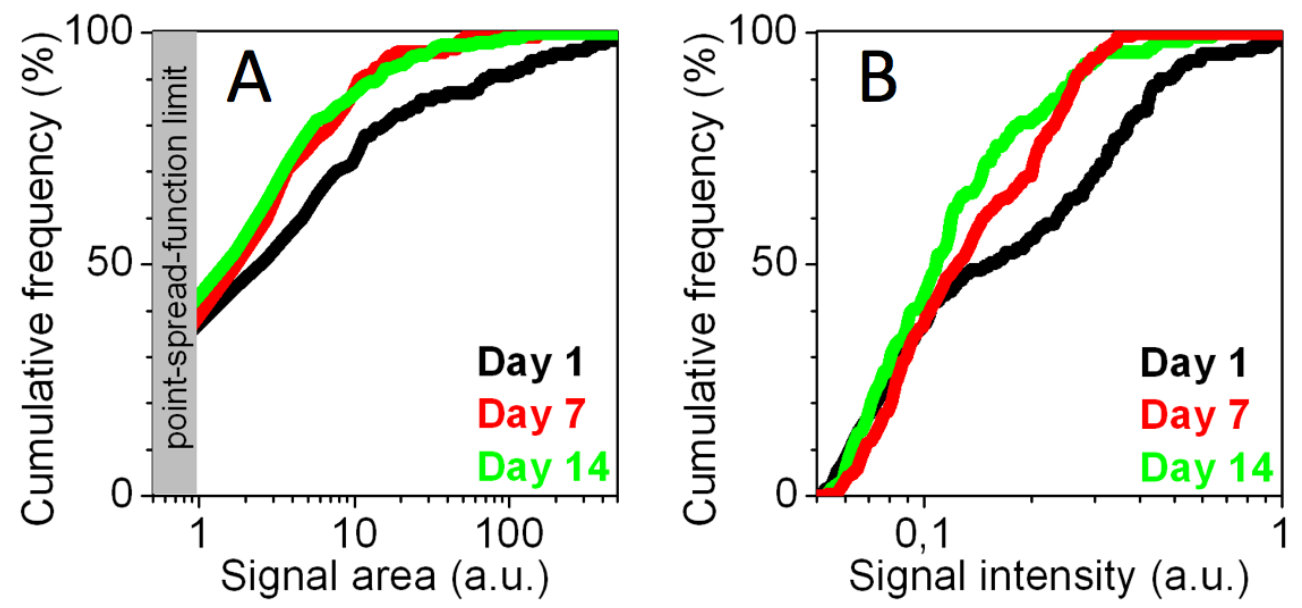

Figure 3. Analysis of the PhI signal area (A) and intensity (B) related to MWCNT- $\mathrm{NH}_{3}{ }^{+}(10 \mu \mathrm{g} / \mathrm{ml})$ in microglial cells after 1 to 14 days. The graphs represent the cumulative distributions, normalized to 100 , of PhI signal areas and intensities detected in cells $(131,119$ and 334 analyzed areas in 9, 7, 14 cells for 1,7 and 14 days respectively).

Both evolutions of signal areas and intensities from day 1 to day 14 indicate that nanotubes become sparser and less absorptive (Figure 3A and 3B, respectively), consolidating the idea of their intracellular degradation as suggested by observations in Figure $\mathbf{2}$ and as previously reported for the same nanotubes using Raman spectroscopy. ${ }^{29}$ Interestingly, at day 7 and day 14, histograms of signal areas (Figure 3A) are almost identical, while signal intensities (Figure 3B) are smaller at day 14 than at day 7 . This led us to speculate that the intracellular nanotube degradation may start by a combined process of de-agglomeration and shortening of the MWCNTs from day 1 to day 7 (i.e. combined area and intensity reduction) followed by thinning of the nanotube diameters via degradation of their outer walls beyond day 7 (i.e. only intensity reduction).

Altogether, these findings (Figures 2 and 3) suggest the intracellular degradation or removal of MWCNTs and thus confirm previous evidence of intracellular degradation of these same nanotubes stereotactically injected into mouse brain or cultured in isolated primary microglia (using TEM, Raman spectroscopy, or both). ${ }^{5,29}$ However, our present investigations revealed 
that for characterizing the evolution of CNT content in biological samples, PhI presents key advantages with respect to TEM and Raman spectroscopy, which are currently the two main established methods for such characterizations. In particular, and in contrast to both TEM and Raman spectroscopy/imaging, $\mathrm{PhI}$ has the advantage of getting no interference from biological matrix components that could hamper the CNT degradation analysis (i.e. carbon in carbonbased matrix and auto-fluorescence, for TEM and Raman, respectively). In addition, PhI allows exploiting the standard preparation procedures of biological samples used for other microscopic analysis techniques, such as resin embedding for TEM or paraffin embedding for histology. The possibility to prepare one biological sample for multiple observations such as PhI and TEM or $\mathrm{PhI}$ and histology allows the development of correlative microscopy strategies. This could be of high interest to further study the intracellular trafficking and fate of CNTs in combination to evaluating their biological impact.

In summary, this study provides the evidence that $\mathrm{PhI}$ can be used alongside TEM and Raman spectroscopy as a simple characterization technique for both in situ visualization and evaluation of MWCNT degradation in cells as a function of time. Moreover, PhI does not share the limitations of TEM and Raman spectroscopy in regards to in situ CNT degradation evaluation. Finally, this technique can easily be expanded to any biological samples as specimen preparation requirements are similar to other analytical microscopies (TEM, histology).

Electronic Supplementary Information (ESI) available: Experimental section including materials and methods. See DOI: $10.1039 / \mathrm{x} 0 \mathrm{xx} 00000 \mathrm{x}$

\section{Acknowledgements}


This work was supported by the Centre National de la Recherche Scientifique (CNRS), DGA, the International Center for Frontier Research in Chemistry (icFRC), the France-BioImaging national infrastructure (ANR-10-INBS-04-01), IdEx Bordeaux (ANR-10-IDEX-03-02), the Agence Nationale de la Recherche (ANR) (ANR-14-OHRI-0001-01 \& ANR-15-CE16-000403) and by ANR through the LabEx project Chemistry of Complex Systems (ANR-10-LABX0026_CSC). CB would like to acknowledge a fellowship from the European Commission, under the FP-7 people Marie Curie Actions (Career Development Intra-European Fellowship, FP7- PIEF-GA-2010-276051, project NANONEUROHOP). M.P. acknowledges financial support from AXA Chair program.

\section{References}

1 A. Bianco, K. Kostarelos and M. Prato, Chem. Commun., 2011, 47, 10182.

2 G. P. Kotchey, S. A. Hasan, A. A. Kapralov, S. H. Ha, K. Kim, A. A. Shvedova, V. E. Kagan and A. Star, Acc. Chem. Res., 2012, 45, 1770-1781.

3 G. P. Kotchey, Y. Zhao, V. E. Kagan and A. Star, Adv. Drug Deliv. Rev., 2013, 65, 1921-1932.

4 D. Elgrabli, W. Dachraoui, C. Ménard-Moyon, X. J. Liu, D. Bégin, S. Bégin-Colin, A. Bianco, F. Gazeau and D. Alloyeau, ACS Nano, 2015, 9, 10113-10124.

5 A. Nunes, C. Bussy, L. Gherardini, M. Meneghetti, M. A. Herrero, A. Bianco, M. Prato, T. Pizzorusso, K. T. Al-Jamal and K. Kostarelos, Nanomedicine (Lond), 2012, 7, 1485-1494.

6 J. Russier, C. Ménard-Moyon, E. Venturelli, E. Gravel, G. Marcolongo, M. Meneghetti, E. Doris and A. Bianco, Nanoscale, 2011, 3, 893-896.

7 B. L. Allen, P. D. Kichambare, P. Gou, I. I. Vlasova, A. A. Kapralov, N. Konduru, V. E. Kagan and A. Star, Nano Lett., 2008, 8, 3899-3903.

8 J. Bartelmess, S. J. Quinn and S. Giordani, Chem. Soc. Rev., 2015, 44, 4672-4698.

9 A. R. Sureshbabu, R. Kurapati, J. Russier, C. Ménard-Moyon, I. Bartolini, M. Meneghetti, K. Kostarelos and A. Bianco, Biomaterials, 2015, 72, 20-28.

10 Y. Zhao, B. L. Allen and A. Star, J. Phys. Chem. A, 2011, 115, 9536-9544.

11 L. Cognet, S. Berciaud, D. Lasne and B. Lounis, Anal. Chem., 2008, 80, 2288-2294.

12 P. Vermeulen, L. Cognet and B. Lounis, J. Microsc., 2014, 254, 115-121.

13 S. Berciaud, L. Cognet, G. A. Blab and B. Lounis, Phys. Rev. Lett., 2004, 93, 257402.

14 M. Selmke, M. Braun and F. Cichos, ACS Nano, 2012, 6, 2741-2749.

15 D. Boyer, P. Tamarat, A. Maali, B. Lounis and M. Orrit, Science, 2002, 297, 1160-1163.

16 V. P. Zharov, V. Galitovsky and M. Viegas, Appl. Phys. Lett., 2003, 83, 4897.

17 A. Gaiduk, M. Yorulmaz, P. V. Ruijgrok and M. Orrit, Science, 2010, 330, 353-356.

18 D. Lasne, G. A. Blab, S. Berciaud, M. Heine, L. Groc, D. Choquet, L. Cognet and B. Lounis, Biophys. J., 2006, 91, 4598-4604.

19 C. Leduc, S. Si, J. Gautier, M. Soto-Ribeiro, B. Wehrle-Haller, A. Gautreau, G. Giannone, L. Cognet and B. Lounis, Nano Lett., 2013, 130306160416009.

20 M. A. van Dijk, M. Lippitz and M. Orrit, Acc. Chem. Res., 2005, 38, 594-601.

21 S. Berciaud, L. Cognet and B. Lounis, Nano Lett., 2005, 5, 2160-2163.

22 S. Berciaud, L. Cognet, P. Poulin, R. B. Weisman and B. Lounis, Nano Lett., 2007, 7, $1203-$ 1207. 
23 C. Leduc, J.-M. Jung, R. R. Carney, F. Stellacci and B. Lounis, ACS Nano, 2011, 5, 2587-2592.

24 P. Zijlstra, P. M. R. Paulo and M. Orrit, Nat. Nanotechnol., 2012, 7, 379-382.

25 J. Olson, S. Dominguez-Medina, A. Hoggard, L.-Y. Wang, W.-S. Chang and S. Link, Chem. Soc. Rev., 2015, 44, 40-57.

26 S. Berciaud, D. Lasne, G. A. Blab, L. Cognet and B. Lounis, Phys. Rev. B, 2006, 73, 045424.

27 L. Cognet, C. Tardin, D. Boyer, D. Choquet, P. Tamarat and B. Lounis, Proc. Natl. Acad. Sci. U.S.A., 2003, 100, 11350-11355.

28 Z. Gao, L. Oudjedi, R. Faes, F. Moroté, C. Jaillet, P. Poulin, B. Lounis and L. Cognet, Sci. Rep., 2015, 5, 17093.

29 C. Bussy, C. Hadad, M. Prato, A. Bianco and K. Kostarelos, Nanoscale, 2016, 8, 590-601.

30 H. Ali-Boucetta, A. Nunes, R. Sainz, M. A. Herrero, B. Tian, M. Prato, A. Bianco and K. Kostarelos, Angew. Chem. Int. Ed., 2013, 52, 2274-2278.

31 V. Georgakilas, N. Tagmatarchis, D. Pantarotto, A. Bianco, J.-P. Briand and M. Prato, Chem. Commun., 2002, 3050-3051.

32 K. T. Al-Jamal, L. Gherardini, G. Bardi, A. Nunes, C. Guo, C. Bussy, M. A. Herrero, A. Bianco, M. Prato, K. Kostarelos and T. Pizzorusso, Proc. Natl. Acad. Sci. U.S.A., 2011, 108, 10952 10957.

33 J. E. Podesta, K. T. Al-Jamal, M. A. Herrero, B. Tian, H. Ali-Boucetta, V. Hegde, A. Bianco, M. Prato and K. Kostarelos, Small, 2009, 5, 1176.

34 L. G. Delogu, G. Vidili, E. Venturelli, C. Menard-Moyon, M. A. Zoroddu, G. Pilo, P. Nicolussi, C. Ligios, D. Bedognetti, F. Sgarrella, R. Manetti and A. Bianco, Proc. Natl. Acad. Sci. U.S.A., 2012, 109, 16612-16617.

35 K. T. Al-Jamal, A. Nunes, L. Methven, H. Ali-Boucetta, S. Li, F. M. Toma, M. A. Herrero, W. T. Al-Jamal, H. M. M. ten Eikelder, J. Foster, S. Mather, M. Prato, A. Bianco and K. Kostarelos, Angew. Chem. Int. Ed., 2012, 51, 6389-6393. 